\title{
\$ocietp Proceedings
}

\section{NEW YORK NEUROLOGICAL SOCIETY.}

December 5, 1905 .

The President, Dr. Josepr Fraenkel, in the Chair.

$A$ Case of Blindness, with Astereognosis.-This was presented by Dr. J. F. Terriberry. The patient was a man; 55 years old; a native of Canada; married, and of intellectual pursuits. His father met a violent death at the age of 30 ; his mother died at 70 of "dropsy." He stated that he came from a healthy stock, with no hereditary entailments. He was strong and vigorous in his early life, and continued to enjoy good health ip to the time of his present trouble. He married at the age of 22 , and shortly thereafter entered the Canadian Parliament, pursuing an active career in statecraft for a number of years. Following this, he engaged in railroad work in its various phases, until his present trouble incapacitated him.

For a period of about twelve years, after the age of 40 , he used alcoholics freely but not steadily, and was exposed to venereal disease. He admitted having had gonorrhea and a soft chancre, but denied syphilis. He denied having been injured, and gave no history of malaria or rheumatism. He was greatly disturbed by business misfortunes and reverses for some years prior to his present illness.

Between three and four years ago, while his general health was apparently good, he became aware of a slight indistinctness or blurring of his vision, both eyes, seemingly, being equally affected. His vision slowly but steadily failed for a year and a half to two years, when it was reduced to its present condition of light form perception only. This failure of sight had been unaccompanied by symptoms of any kind until about one year ago; he had had no headache, no dizziness, nausea or vomiting, no phenomena of irritation of the visual tracts. About a year ago his wife noticed some awkwardness in his movements while dressing, and this had gradually become more marked, particularly on the left side.

Upon examination, the patient presented a good general appearance. He was well nourished, and his complexion was good. His face had the blank expression of a sightless person. The left shoulder drooped a little. The left hand, in repose, gave an expression of weakness quite evident when contrasted with the right. He was able to stand and walk well. There was no tremor of the hands, tongue or facial muscles.

The left knee-jerk was normal; the right was present, but less active. The Achilles jerks were obtained, but their action was slight.

Stroking the soles of the feet caused slight flexion of all the toes excepting the great toe, which remained motionless. No Babinski. The tendon reflexes of the upper extremities were normal. A chin reflex was obtained. Tapping the branches of the facial nerve elicited no response. (The pupils were regularly and equally dilated to double normal size. Lioht reflex was present, but reduced, and attempts at psychic accommodation by imagining that he was looking at near and remote objects caused no action in the pupils.) The senses of smell and taste were apparently normal. a watch was heard at the normal distance.

The patient was now handed a dynamometer and requested to grip it with all his strength, when it at once became apparent from the awk: ardness with which he handled the instrument that there was som- 
difficulty with the stereognostic perception. Placing the instrument proper$1 \mathrm{y}$ in his grasp, he recorded with the right hand, 18,32 and 25 ; with the left hand, 25,25 and 22 .

The patient was requested to raise his arms above his head: this he did hesitatingly, raising the left arm part way only. He was asked to execute a number of arm movements, and was found utterly unable to do so. A number of different objects were placed in his hands, none of which he could name properly. His arms were placed in various positions, and he was unable to say what the positions were. In all of these movements, the left side was less competent, if possible, than the right. When asked to stand on the right foot, he stood on the left, and vice versa, or, apparently guessed at it. The muscle sense in the arms was absent and was very poor in the legs below the knees. When asked to cross his legs, he did so poorly. The sense of touch was good in the upper and lower extremities, and the same was true of pain and temperature perceptions. There was, however, some delay in recording these impressions. The localizing sense was nil. There was no ataxia of the upper or lower extremities. The bladder and rectal functions were normal. There was no change in his disposition.

Attempts at determining the condition of the visual memories were not conclusive, but were suggestive of partial failure. When asked if he recalled the appearance of his friends, he replied that he could recall the sound of their voices much rather than their appearance, and he believed that his memory for things seen was not good. The ophthalmoscope revealed a normal looking fundus. The urine was normal; the blood examination negative.

Dr. David Webster, who had made repeated examinations of the eyes of the patient shown by Dr. Terriberry, said there was nothing in the appearance of the optic nerves that would account for the loss of vision. At first, he had been inclined to believe that he saw evidences of a retrobulbar neuritis, but subsequent examinations by himself and his colleagues had failed to substantiate that diagnosis. The patient still had some vision, and it was apparently growing no worse. He was unable to count fingers, but distinguished objects that were placed before his face. and was able to exercise regularly in the corridor of the hospital without coming in contact with objects. The astereognosis, which was first noticed by Dr. Terriberry. was a very interesting symptom. Any piece of paper that was placed in the patient's hand he would simply recognize as money. His symptoms pointed to a cortical degeneration, which had perlaps invaded the visual centres. The case might be put down as one of visual astereognosis. Two or three weeks ago the patient first began to suffer from nocturnal incontinence, which was corrected by the use of the tincture of belladonna.

Dr. William M. Leszynsky said he had had the opportunity of examining the patient shown by Dr. Terriberry, and could corroborate all that had been said in regard to the symptoms. An interesting question to decide was whether the man's blindness was due to a lesion of the optic centres, or to one anterior to the corpora quadrigemina. This could not be satisfactorily determined from a study of the reaction of the pupils, as atropine had been instilled daily.

The speaker said lye was inclined to the diagnosis of diffuse cortical degeneration involving the parietal and occipital areas, this being secondary to arterial chances.

Dr. Terriberry. in closing, said the duration of the man's illness was about four vears. during which time there was a gradually increasing loss of sight. No other symptoms were noticed until a year ago. While the diagnosis was snmewhat in doubt, the case was probably one of cortical degeneration. The etiological factor for this had not been made out. The man had used alcohol. but not to excess; he had never been injured; he denies having had syphilis. The change apparently began in the occipita 
region and extended forward toward the motor area, a little farther on the right side than on the left.

Osteoma of the Spine in the Cauda Equina Region.-By Drs. Max Mailhouse and William F. Verdi, of New Haven, Conn. The patient was a man, 44 years old, a widower. His family history was unimportant. He denied all venereal disease, and had two healthy grown-up children. For one year prior to the onset of his symptoms he had smoked and drunk to excess. Early in the summer of I905, he had first noticed increased sexual desire, at times going to the extent of four or five sexual acts daily. He consulted Dr. Verdi on account of pain in the hypogastric region coming on in paroxysms, the first of which accurred in July. The pains were not very severe at first, but as time went on they increased both in severity and frequency. Subsequently, he began to complain of severe backache, also in paroxysms, at times brought on and aggravated by movement of the spine. An attack that occurred while he was sitting up was so severe that he could not bear to be removed to his bed. The pain radiated from the suprapubic region to the back, where he located it at about the second lumbar vertebra, a little to the left. Later on the pain in the back became constant, and soon after, severe pain in the testicles appeared, also paroxysmal, which was present at times together with the hypogastric pain. Subsequently, the pain extended to the upper and inner part of the thighs, and he also described the pain at times as passing straight from the pubis to the spine. During this period of suffering, he had lost about twenty pounds in weight; his pulse had become small and frequent, and he could sleep but little without the help of anodynes.

In addition to his spinal symptoms, the patient had noticed in August that his eyes began to ache, and early in October he observed that the vision in his left eye was failing. On October 17 , he consulted Dr. A. 'N. Alling. who found a retrobulbar neuritis, as evidenced by a central scotoma, the disc appearing normal.

When Dr. Mailhouse first saw the patient, on November I, I905, he obtained the same history as did Dr. Verdi. There was no spinal tenderness, and nothing visible on the back. There was no anaesthesia nor analgesia on the trunk, legs, buttock, genitals or perineum; no paralysis; no contractures. The patient was able to stand on either leg. The knee-jerks were active, but there was no ankle--clonus nor Babinski. The plantar reflexes were extremely lively, and tactile sense very acute. Kernig's sign was marked. The general musculature was flabby, but there was no focalized atrophy; no special idio-muscular contractility. No vesical symptoms were present. On November 12, there was observed some weakness of the left internal rectus, as evidenced by a deviation of the left eye.

Diagnosis: Owing to the absence of vesical symptoms, and a loss of sensation of any kind, as well as the absence of paralytic phenomena and of marked changes in the deep reflexes. Dr. Mailhouse said he located the lesion below the contus, and considered it an irritative lesion of the nerve roots supplying the ilio-hypogastric, ilio-inguinal and genitocrural nerves; hence of the first and second lumbar roots, and inasmuch as the conus was not involved, he thought the seat of the irritation must be near the region of the second lumbar vertebra. A diagnosis was thereupon made of a tumor pressing upon the cauda equina at the level of the second lumbar spine, and, owing to the prominent irritative phenomena and the absence of motor involvement. and to the simultaneous involvement of the second and third cranial nerves, it was supposer to be a gumma.

Operation: This was proformed on November 2I, by Dr. Verdi, assisted by Drs. Wm. H. Carmalt and L. W. Bacon, Jr. The spines and laminæ of the first and second lumbar vertebræ were removed, and nothing but a tense dura found. On removing the spine and upper edges of the third vertebra, however, the dura was seen to be pushed forward and com- 
pressed against the body of the bone at an acute angle, and the finger could feel a bony growth occluding the canal. The remainder of the laminz and the tumor were then removed with the biting forceps, as the condition of the patient did not warrant a prolongation of the operation, such as the use of the saw and the removal of the tumor en masse would necessitate. It was estimated that the antero-posterior measurement of the tumor was five-eighths of an inch, and its vertical measurement half an inch.

Immediately on removal of the compressing body, the distorted dura returned to its normal position. The left half of the growth seemed to be slightly larger. In consistence it was decidedly harder than the lamince as experienced by the operator in its removal.

Two weeks had now elapsed since the operation. The wound had healed and the patient was able to sit up and was entirely free from pain excepting that referable to the wound. The eye symptoms were reported to have progressed to the degree of some ptosis, indicating greater involvement of the third nerve. The nature of the ocular affection had not as yet been determined. It apparently had no connection with the spinal lesion.

The President, Dr. Fraenkel, said these cases of usteoma of the spine were of very rare occurrence. He recalled a case seen seven or eight years ago in which there were evidences of a progressive intraspinal lesion, and which was explained at the autopsy by an osteoma of the processus odontoides atlantis.

Retro-Pharyngeal Carcinoma, with Metastases.-Dr. B. Sachs reported this case, and showed the specimen. The patient was a man, 35 years old, who was admitted to the Mt. Sinai Hospital last summer while Dr. Hirsch was on duty. The symptoms indicated increasing intracranial pressure, with more or less somnolence, slight hemiplegia, right-sided oculomotor palsy, and a double optic neuritis. The symptoms pointing to an, intracranial growth were connected with a large retropharyngeal mass, which was regarded as the source of his trouble, and was supposed to have perforated the base of the skull.

The patient's symptoms gradually became more aggravated, headaches were intense, and multiple tumors developed in the scalp and various parts of the body. The retropharyngeal growth was rather soft to the touch, and was at first supposed to be a gumma. A section of the growth was submitted to Dr. E. Libman, of the Pathological Department of the Hospital, who. upon examination, found it to be a carcinoma.

The case resulted fatally. and the skull of the patient, which was exhibited by Dr. Sachs, showed multiple perforations, indicating the sites of the metastatic cancerous growths.

A Case of Brain Tumor.-Reported by Dr. William M. Leszynsky, with specimen. The patient was a male; 28 years old; single; born in Russia; a photographer. He was admitted to the Lebanon Hospital on October 28, 1903, with the following history: His father died of diabetes; his mother and sister wcre living and in good health. During childhood he had measles and scarlatina. without sequelae. He attended school, ind was well developed mentally and physically.

His sister stated that when he was four years old he was struck on the forehead by a stone, which resulted in momentary loss of consciousness, but no further trouble followed. At the age of 13 , he was frightened at the sight of the killing of a mad dog, and at once became hysterical and had convulsive fits several times daily for about three weeks. Soon after, his hands and feet began to shake almost constantly, and he would often fall asleep while standing, walking or eating. He recovered from this condition at the end of two years, and came to this country at the age of $\mathbf{1 5}$. Since then he had often com- 
plained of heaviness in his head, and when once asleep, it was very difficult to arouse him.

About nine months ago he began to suffer from frequent attacks of severe general headache, preceded or accompanied by vomiting, and this had continued. About two months ago, vision began to fail, and blindness soon supervened. He now complained of headache, vertigo and general weakness, with a sensation of falling toward the right side. His appetite was fair; bowels regular; urination frequent. $\mathrm{He}$ had been moderate in the use of alcoholics. He admitted having contracted gonorrhea, but denied syphilitic infection, and presented no evidence of that disease.

Exanination on admission showed a well nourished, intelligent young man, weighing 140 pounds. Hc was obliged to remain abed, being unable to stand or walk without assistance. His pulse was 84; regular. Temperature and respiration, normal. The heart, lungs, and abdominal viscera were normal. There was no tenderness on percussion over the skull; no rigidity of the neck muscles; both pupils were equally dilated and immovable; no nerception of light in either eye; ocular motility normal; bilateral papillitis of six diopters, with numerous retinal hemorrhages; smell and hearing normal; slight left facial paresis of the lower branches; the gasp was weaker on the left side, and there was slight uncertainty in distinguishing objects with the left hand. Muscular power and resistance were otherwise good in all extremities. Both knee-jerks were equally active; no clonus; plantar, Achilles, cremasteric and abdominal reflexes normal. No objective sensory disturbance. Urine and blood examinations negative.

The patient was delirious at times, and had occasional attacks of headache and vomiting. These symptoms were relieved by cathartics and suitable diet. He gradually became worse, the symptoms, increasing in intensity, and there was paralysis of the right external rectus. The grasp became decidedly weaker in the left hand, and there was occasional flexor rigidity of the entire extremity. Left asrereognosis was pronounced, but disappeared from time to time. It persisted for minutes, hours, or days, being present and demonstrated at one examination and absent at another. Slight ataxia was present in the left hand, but muscular sense and the sense of position were preserved, and there was no disturbance of tactile, pain or temperature sensibility. There was diminished resistance in the left posterior thigh group; the left knee-jerk and Achilles reflex were exaggerated, and pseudo-clonus with general trepidation of both lower extremities were present, being more marked on the left side; both plantar reflexes were exccssive, but of normal type. From time to time both lower extremities became rigidly extended and hyperaesthetic, when the slightest handling would produce extreme trepidation of both limbs, lasting several minutes.

$\mathrm{He}$ was kept in bed, and, in addition to general manngement, iodide of potassium was administered in increasing doses. Rapid improvement in all symptoms soon followed. Two months later, (December, I903) the astereognosis, ataxia and external rectus paralysis had completely disappeared, the retinal hemorrhages had become absorbed, and the elevation of the optic nerves had receded to four D. The headache, vertigo, and vomiting had entirely subsided, and his general health was much improved.

In February, 1904, with the exception of the blindness and beginning optic atrophy, he was apparently in perfect health and able to walk about the wards and corridors without assistance other than the guidance required by a blind man in order to avoid accidents. Several 
$X$-ray examinations were made with negative result. Cerebrospinal fluid (40 c.c.) was withdrawn by lumbar puncture and immediately resilted in a severe attack of headache. Thirty minutes of an aseptic solution of ergot were then given subcutancously, and in a few minutes he fell into a sound sleep lasting about an hour, and awoke free from pain. The fluid was found normal. Lymphocytosis was not present. $\mathrm{His}$ condition being unchanged. he was discharged July 21 , I904.

He was then taken to an institution for the blind, where he remained until re-admitted to the Lebanon Hospital on September 23, 1904. At this time his bodily condition and general health were good. Careful and frequent examinations failed to rcveal any evidence of disease of the ncrvous system, other than commencing postneuritic atrophy. During his thrce months sojourn in the hospital, he occasionally complained of hearlache and vertigo. He was discharged January 1, 1905, and remained at home about six weeks. During this period his memory was good, and he was always rational in his conversation and manner, complained frequently of headache and vertigo, and often said he felt like falling.

Hc was again placed in an institution for the blind for about six weeks. where he became so ill that he was removed to the house of a relative. Whilc there he had frequent attacks of severe and uncontrollable headache, with vomiting, delirium, and general convulsions, with loss of consciousncss, varying in frequency from one attack every twentyfour hours to one every two hours. During the intervals, he was always rational. This condition continuing for several weeks, he was removed to the Kings County Hospital, May 15, Ig05. He was admitted to the service of Dr. A. C. Brush, who noted, in addition to the blindness and papillitis, "memory poor, attention and volition slow; he complained of hcadache, and had occasional outbursts of delirium; examination otherwise negativc in result. The diagnosis of cerebral tumor was made, but the growth was not localized. He remained in the same condition for ten days, and was found clead May 25, 1905."

The autopsy was performcd by Dr. B. Joseph, Resident Pathologist, to whom the speaker is inclebted for the specimen and the following 11otes:

"Skull somewhat enlarged. Calvarium normal. Numerous erosions of the internal surfacc of the right side of the skull. Right hemisphere about onc-third largcr than the left and intimately adherent to the dura. Pia mater on the right side altogether obliterated; on left side edematous. Cerebral cortex on right side thinned. Ventricular cavities filled with about eight ounces of clcar serous fluid. Attached to the right internal surfacc of the right lateral ventricle was a tumor about the size of a hen's egg. of cauliflower-like appearance, and exhibiting discrcte areas of darker and lightcr colors. Upon section, the tumor gave a grating sensation to the knife. The posterior fornix of the right ventricle was enlarged to about twice its normal size No further examination of the brain was conducted. Body section was not permitted. The tumor, upon microscopic examination. proved to be a small round cell sarcoma containing areas of calcareous deposits."

This is the second case of brain tumor occupying the lateral ventricle that has come under the speaker's observation. The first case was reported at a meeting of this Society in December, 1903. Both cases presented the following analogous features:-The patients were intelligent adults; both had frequent attacks of intense headache, vomiting, delirium and convulsions; a high degree of bilateral papillitis accompanied by early, total and permanent blindness; astereognosis, without any disturbance of general sensibility; the absence of paralysis involving the extremities; only a slight transient hemiparesis; the diag- 
nosis of brain tumor involving the right hemisphere was made, but the exact location of the neoplasm could not be determined intra vitam. In both cases the tumor was found in the right lateral ventricle and proved to be sarcomatous.

Dr. Leszynsky said that on account of the marked and rapid improvement following the use of potassium iodide, it was thought for a time that a mistake had been made, and that the case was one of syphilitic basilar meningitis, but the autopsy proved otherwise.

Dr. Arthur C. Brush, of Brooklyn, who had seen the case reported by Dr. Leszynsky, said that while the patient was under his care he had shown the symptoms of brain tumor, but at that time it would have been difficult to localize it. No history was obtainable from the patient. He was dull and apathetic, and the answers he made to questions were not to be relied upon.

Familial Multiple Sclerosis.-Dr. I. Abrahanson showed two out of three brothers who were affected with this disease. The history of the three patients was as follows:-Edward M., aged ig years; Louis M., aged 16 years, and John M., aged 15 years, all born in the United States of Bohemian parentage. Both parents and two younger children were alive and well. Two children, also unaffected with this disease, had died in infancy. There was no history of miscarriages. The father positively denied lues; his sister was epileptic; the mother's brother was insane. Otherwise, the fmily history was negative.

Edward $M$. was born prematurely at seven and a half months. His first tooth appeared when he was a year old. He was breast fed. Speech appeared early, and he could walk at eighteen months. He developed into a stong and bright infant. $\mathrm{He}$ had scarlet fever, measles, pertussis and varicella. At the age of six years he had his first epileptic seizure. There was an infrequent recurrence of these seizures; they were chiefly nocturnal and ceased in a year or two. Three and a half years ago he had malaria, and following it there was a return of the epileptic attacks, slight in character, being more tonic than the former fits. They also were nocturnal. About the same time, unsteadiness in the hands was noticed; later, tremor and some weakness, change in speech intonation and right-sided headaches. Subsequentlv, there was some unsteadiness in walking, but this was never so decided as in the other two patients. The special senses were not involved; the sphincters remained intact. $\mathrm{He}$ was formerly a fair penman, but his writing became very tremulous, and at times illegible. He had to give up his position as druggist's assistant, and now acted as a driver on a wagon. He was always much brighter than the other two boys. Of late, an alteration in his facies had been noticed, his cheeks having become sunken.

Examination showed a tall lad, fairly well-nourished, with many stigmata of degeneracy. His gait was fairly good, but attempts at balancing showed unsteadiness. There was no Romberg. The pupils were equal and reacted normally. The ocular movements showed some nystagmiform twitchings in extreme positions. There was a tremor of the facial muscles and some tremor of the tongue. The left pharyngeal innervation was stronger than the right and the pharyngeal reflex was present. There was some tremor of the head; the laryngeal movements were normal; triceps and wrist jerks were present; motor power in the upper extremities was fair; myotatic irritability normal; there was a coarse oscillatory tremor of the hands when extended; ataxia in the upper extremities; deep sensibility was unimpaired; the heart, lungs and viscera were normal; the abdominal and cremasteric reflexes were present; some scoliosis; knee jerks and Achilles jerks lively; no clonus; Babinski present on both sides; motor power in lower extremities normal; some unsteadiness; general sensibility unimpaired, strbjectively 
and objectively; optic discs showed temporal atrophy; no limitation of the visual fields; hearing normal; range normal; other special senses unimpaired; no atrophy nor vaso-motor disturbances; speech rather monotonotis, and not as scanning as was the case with his brothers. The course of the discase was not steady, as there were distinct remissions and exacerbations; no forced laughter. $\mathrm{He}$ was decidedly. the least involved of the three.

Louis M., born at full term; breast fed; first tooth at one year; walked at eighteen months, speech early; strong as a child, but never bright. Had pertussis, measles and varicella. When he was seven years old he had his first epileptic fit. These attacks were frequent and general in character; chiefly nocturnal. Soon after the onset of his epileptic seizures, tremulousness of the hands was noticed. Later on, the tremor spread to the body and the head, and at the same time unsteadiness in the hands dcveloped, together with a progressive alteration of the gait, which became shuffling and unsteady, especially on exertion. The speech also became progressively involved. The facies changed in the course of time, and a tremor of the right face was noticed, especially when speaking or exerting himself in any way. His writing, which was once intelligible, was now a scrawl. The sphincters were unimpaired. The patient complained of paraesthesia of the hands. There was no forced laughter.

Examination showed a rather undersized lad; stooped; left shoulder ligher than the right; sunken cheeks; listless, unintelligent face; movement of the right facial muscles; marked head tremor when walking, etc.; gait shuffling and unsteady; slight stiffness; no Romberg; pupils equal and reacting normally; nystagmiform movements in extreme positions; right facial innervation stronger than the left; fibrillary tongue tremor; tremor of the pharyngeal and laryngeal muscles upon intention; coarse oscillatory tremor of the hands and conveyed to the body; unsteadiness in the upper extremities; decided intention tremor; motor power fair; deep sensibility normal; wrist jerk normal; triceps. lively; no wasting; scoliosis, with convexity to the left; heart, lungs. and viscera normal. Upper abdominal and cremasteric reflexes present: knee jerks lively; Achilles lively; no clonus; Babinski on both sides; big toes in constant extensor position; extension of the first phalanges. and flexion of the rest. Motor weakness in the lower extremities; ataxia present; no loss of deep muscular sensibility; general sensibility intact; optic disc showed atrophy in both eyes; vision normal; range normal; speech distinctly monotonous and scanning; intelligence decidedly sudnormal. In this patient the somatic signs were most marked.

John M., birth norinal; breast fed; first tooth at one year; walked at eighteen months; speech at two years; speech very slow and indistinct, even at the start. The patient had measles, varicella and pertussis. His intellectual condition was always subnormal. The first symptom of his prescnt illness was tremor and unsteadiness in the hands. At the age of nine he had his first epileptic attack; these recurred at irregular intervals, and were always nocturnal. He had frequent diurnal headaches; never dizziness.

Examination showed a poorly nourished lad, stooped; scoliotic; sunken cheeks; many stigmata of degeneracy; pupils normal; some weakness of both external recti, and nystagmiform twitchings in extreme positions; tremor of the facial muscles upon intention; fibrillary tremor of the tongue; pharyngeal reflex present; head tremor upon intention; deep reflexes of the upper extremity present; oscillatory tremor of hands when extended; also intentional tremor; ataxia in the upper cxtremities. As in the other cases, closure of the eyes did not: accentuate the tremor nor unsteadiness. Lungs and kidneys normal; 
mitral insufficicncy; other viscera normal; cremasteric and lower abdominal reflexes absent; scoliosis; knee jerks and Achilles lively; Babinski both sides; unsteadiness in lower extremities; deep sensibility intact; general sensibility normal; special senses normal; optic discs normal; speech scanning and very indistinct; intelligence markedly subnormal; no forced laughter.

The Etiology, Prognosis and Treatment of General Paresis.-Dr. Joseph Collins, who presented this paper, said that in regard to the etiology of general paresis there seemed to be a remarkable unanimity of opinion existing amongst those who had seen and studied the disease sufficiently to entitle them to the expression of an opinion. Kraft-Ebing summarized our knowledge of the subject in his statement that synhilization and civilization were the cause of the disease. It was probable that neither one was an adequate and determining cause. In uncivilized countries where syphilis existed, general paresis was unknown, but as civilization disseminated, general paresis crept in. The factors of civilization that contributed to the causation of general paresis need not be discussed. It was an intangible something that proceeded pari passu with the progress of civilization, apparently, for general paresis was more frequent with each succeeding generation. We called it strife and worry and work, without knowing that it was any of these. It might be a habit of life; it might be the food we ate; it might be an evolutionary condition that allowed a certain flora to develop in the gastrointestinal tract, and so provide the initial step for the development of the disease.

Dr. Collins said that in order to introduce a discussion of the causation of the disease, he had taken the last roo cases of general paralysis he had seen, 50 from private practice and 50 from hospital practice, and had analyzed them. This comparatively small number had been taken, first, because they were fairly complete; and, second, because it seemed to him that as much and as reliable data could be gotten from roo cases as from 500 .

Of these roo patients, 85 were males and 15 were females. So far as professions and occupations were concerned, it was difficult to find one that was not represented. There were clergymen, physicians, jurists, statesmen, bankers, capitalists, and laborers and artisans of all sorts. Of the roo cases, there were no less than 23 in which there was a history in the ancestry of organic or functional nervous disease of sufficient sevcrity to be noted by the family of the patient.

Syphilis: A histoy of syphilis was obtained in 55 of the roo cases, and denied or not obtained in 45 . There was a history of injury in nine cases; in 54 cases there were no excesses; in 23 there were moderate excesses, and in 23 this was admitted as an excessive factor. 73 of the cases were of the paretic type; 27 of the tabetic type. In addition to the 55 who admitted and who were in a mental condition to state that they had had syphilis, there were seven whose collateral history made it fairly certain that they had suffered from that infection. This made a total of 62 out of 100 in which it was certain that a syphilitic infection had existed. In two other cases there was presumptive evidence of a syphilitic infection. This left 23 patients who denied syphilis, and who gave no evidence of its ever having existed. On the other hand, there were many patients seen for the first timc in a more or less advanced stage of the disease, who were not in a mental condition to give reliable information as to whether they had or had not had syphilis.

The average age at which these Ioo patients had syphilis was 25 years, and the average age when general paresis developed was 36 years; thus about eleven years was the average period that elapsed between the infection and the development of the first symptom of the disease. In many cases, however, the time between the existence of 
the chancre and the development of the first symptom of general paresis was very short: for instance in one case the specific lesion developed at the age of 36 and the general paresis at $4 \mathrm{I}$; in another case the syphilitic infection occurred at $3 \mathbf{I}$, and the first symptoms of general paresis at 34 .

Alcohol had a definite relationship to the development of general paresis, but here again the question was whether or not it was in itself a competent, producing cause. Dr. Collins said that in his opinion it was not.

When one approached a discussion of the treatment of general paresis, he was confronted at once with the fact that it was practically universally conceded that the disease was incurable. The speaker referred to the use of mercurials in massive doses, as recommended by Leredde and others of the French school, and stated that his own experience with the intensive mercurial treatment of tabes and general paresis now extended over a period of five years, during which time he had treated many patients in this way. In no instance had he seen intensive mercurialization to be of any service whatsoever in general paresis after the disease had been fully developed; $i$. e., after it had the ordinary somatic and psychical signs, even though the latter were not pronounced. He had had three cases in which it seemed to him that the disease had been arrested in its development; not cured, because the physical signs of the disease still remained.

In concluding his paper, Dr. Collins emphasized the importance of an earlier recognition of the disease.

Dr. M. Allen Starr said that from his own experience he could corroborate much that Dr. Collins had said in regard to the etiology of general paresis. A year ago Dr. Edward L. Hunt, one of his assistants at the Vanderbilt Clinic, went over the statistics of the Clinic for the past seven years and analyzed the cases of general paresis that had come uncler observation there. The result of his investigations corroborated to a large extent the statement made by Dr. Collins, and the same was true of an analysis of one hundred consecutive cases seen by Dr. Starr during the earlier years of his practice. Of those one hundred cases, the histories were practically complete, the patients having died. The statistics, both from his personal and dispensary cases, agreed very closely. Over 59 per cent. were clearly, unquestionably syphilitic. Of the cases he had seen in private practice, 64 per cent. were undoubtedly syphilitic. The speaker said that he differed with the statement of certain French and German writers that all cases of general paresis and tabes were syphilitic: on the contraiy, he believed that in many instances, both of these affections were distinctly non-syphilitic. Many, as Dr. Collins had said, were due to trauma and many were due to alcoholism, and a certain number could not be accounted for on any of these grounds, but were due to the wearing out of the brain tissue in connection with the stress and strain incident to the worry of an active, energetic life.

Dr. Starr said that an analysis of a large number of cases of general paresis had convinced him that the early symptoms of the disease did not cortespond very closely with the statements in the text-books. In only 20 per cent. of the cases he had observed were there any mental symptoms at the outset, leaving about 80 per cent. in which the physical symptoms appeared before the mental phenomena. In the latter cases there was no exaltation; no failure of memory at the beginning. The speaker emphasized, as Dr. Collins had done, the importance of a careful physical examination in every case of so-called neurasthenia. because the early symptoms of general paresis manifested themselves in ways that would tempt one to make the diagnosis of neurasthenia if one contented himself with a superficial examination. The presence 
of the Argyll-Robertson pupil, a tremor of the face and tongue, marked exaggeration of the knee-jerks or their persistent absence were significant early symptoms of general paresis. Another symptom which the speaker had found of considerable importance was what he called the reaction time of the patient. This was mesasured by means. of the Galton instrument, which consisted of a pendulum swinging backward and forward in exactly one second. The pendulum could be immediately started and arrested by the pressure of a finger on a key. The patient sat with his finger on this key, and was instructed to press the key simultaneously with the exhibition. of a light or color, or upon the striking of a bell. By this method it was a very simple matter to determine the reaction time of the patient. Dr. Starr said he had resorted to this test in many cases of neurasthenia and general paresis, and he had found that in the former condition the perception was very keen at the beginning, but gradually decreased after repeated tests, while in general paresis the perception was below the normal from the very start, and the time reaction lengthened as the disease progressed. He thought this test was of some value in differentiating between general paresis and neurasthenia. The differential diagnosis was of great importance because of the question of prognosis and treatment. It was well known that there were cases that presented all the symptoms of general paresis that were actually cases of cerebral syphilis. He recalled such a case where, after a diagnosis of general paresis, the patient recovered under anti-syphilitic treatment, and was now in good health after fourteen years had elapsed. About 15 per cent. of the cases of general paresis began with the symptoms of hemiplegia; about 20 per cent. with the symptoms of neurasthenia and sleeplessness, and about 20 per cent. with some signs of exaltation. This behooved the neurologist to be very careful in his diagnosis, and in every instance the patient should be given the benefit of the doubt and put upon specific treatment.

Dr. B. Sachs said the difficulties of the subject were largely due to the fact that although the greatest effort had been made during the past fifteen years to establish an accurate clinical picture of general paresis, the more closely the disease was studied, the more we became impressed with the idea that the term general paresis unquestionably included a number of very divergent clinical pictures, and for that reason any statistics that were collected would naturally differ and be somewhat misleading. The speaker said he was in entire agreement with Dr. Starr that therc were certain cases of cerebral syphilis or pseudoparesis which could not, at certain stages, be differentiated from genuine dementia paralytica.

In discussing the question of dementia paralytica occurring late in life, Dr. Sachs said that of 283 cases seen at Bellevue in the year 1904 , at least I4 per cent. occurred after the age of fifty; 4 per cent. after fifty-five, while only seven-tenths of one per cent. occurred after the age of sixty. 72 per cent. occurred between the ages of thirty and fifty.

In regard to the interval between the original syphilitic infection and the development of the first symptom of general paresis, Dr. Sachs said he could recall at least two cases in which the mental disorder was recognized within less than one year after the initial infection, and the subsequent course of events verified the diagnosis. He had seen a number of other cases in which the general paresis developed within three years after the chancre.

As to the curability of the disease, Dr. Sachs said he wrote an article some years ago in which he spoke very hopefully of the prognosis, especially if the condition was recognized early. That paper was written some eight years ago, and he was now prepared to make 
one statement very positively. After an experience of over twenty years, during which he had observed several hundreds of cases of general paresis, he could not recall a single instance where the patient had survived over eight years. When the diagnosis of general paresis was honestly and carefully made, the claim could not be established that the disease was curable. In spite of that fact, it would be a great mistake to abandon efforts at treatment. and simply pronounce every case incurable. Mistakes in diagnosis were not infrequent, and with that possibility in mind, the patient should always be given the benefit of the doubt and receive a thorough course of anti-syphilitic treatment. particularly if the case was seen early. While he was far less hopeful in regard to the curability of the disease than he was eight or ten years ago, he still believed that justice to the patient demanded that antisyphilitic treatment should be given a trial.

So far as the etiology of the disease was concerned, Dr. Sachs said he believed there was at least one other important etiological factor besides syphilis, and that was trauma. The same was true in reference to tabes. Syphilis, of course, was the most important factor.

Dr. Adolph Mayer said we should always be prepared to acknowledge that a cliagnosis of general paresis could not be said to be absolutely certain in more than about 90 per cent. of the cases that came under observation under that name. There was a margin of about Io per cent. where we had to depend on the autopsy and anatomical findings, and then the question arose, what anatomical findings should we consider as being conclusive evidence of general paresis, a question which should be discussed to put the entire problem of the etiology and therapeutics of general paresis on a safe basis.

Dr. Meyer said there were, of course, cases in which alcoholism was the only ascertainable etiological factor, while other cases appeared to be due to trauma. We should, however, remember how very difficult it was to absolutely exclucle syphilis in a case of general paresis, and while it. was not necessary nor cven justifiable to proclaim, pro publico that every case of tabes and general paresis must be of syphilitic origin, we could give our statistical facts as evidence in favor of our conviction, and we should with equal sincerity admit that we had no means to exclude previous syphilis positively in any case.

The speaker suggested that when Dr. Starr claimed that in only 20 per cent, of his cases wcre early mental symptoms noted, he must have had in mind the so-called legal insanity. If we took legal insanity as a standard in psychiariry, we would have a poor task in psyciniatric diagnosis. As a matter of fact, we had to clepend on much more subtle evidence, and we would consider above all things the nonconcern over blunders by the patient which madc even slight memory defects appear as an ominous feature. These, and many changes of character and judgment need by no means reach the standards of legal insanity to become decisivc factors in the diagnosis, and were certainly much morc conclusive than changes of reaction time. A great diffculty was connecterl with our ignorance of the bearing of many relatively insignificant dicordcrs that sometimes appeared after syphilis: such, for example, as an Argyll-kobertson pupil. He referred to cases with previous syohilis and perhaps with one Argyll-Robertson pupil, in whom recurient attacks of manic excitement were very difficult to interpret.

With reoard to the arministration of anti-syphilitic remedies, Dr. Meyer sait we should realize that it meant hardly more than a desire to spare the patient the consequences of a possibility of error of diagnosis. It had really no other logical foundation. Inasmuch as there was hardly any reason to fear that a case of cerebro-spinal syphilis would become one of general paresis on account of delay of such treatment. Probablv nothing would be lost in any case if we should wait 
until the diagnosis became more obvious. Under all circumstances, the "result" of such treatment would be a treacheous guide in the diagnosis.

Dr.. H. A. Diefendorf, of Middletown, Conn.; said that on account of the lateness of the hour he preferred not to read his paper on the etiology of general paresis. He wished, however, to record the fact that in his series of 164 cases, in a community one-third of the population of which was rural, he had found that the prominence of the various etiological factors certainly was at variance with that brought out by some of the previous speakers. He had become convinced that excessive alcoholism was an important primary etiological factor, and in some cases he had observed it occurred in over 54 per cent. In his community, the negress paretic was far in excess of the white female paretic, in the proportion of ten to one. In five per cent. of his cases the mental symptoms had immediately followed an injury.

The Etiology of General Paresis:-Dr. M. S. Gregory read this paper, which he said was based on a fragmentary resumé of the writer's clinical experience gained during the past four years in the Psychopathic Wards of Bellevue. Hospital. Over I,000 cases of general paresis had been admitted during that time. The disease had represented 13 per cent. of the total admissions into those wards, and composed 21 per cent. of the total male, and 5 per cent. of the total female insane. patients. The relative proportion of the sexes suffering from genaral paresis had varied from year to year. In 1903 there were more than six times as many male as female naretics; in 1904, the proportion was four to one. For the three years, the average had been five men to one woman. Thus the women represented about 20 per cent of the paretics admitted.

In at least a third of the patients, the histories obtainable were for obvious reasons not as complete as might be desired: many were foreigners, without any friends. and one had to depend largely on the history as given by the patient, who was frequently brought to the hospital following an episodic attack, and was, as a rule, in a condition of extreme mental confusion. Most of the patients admitted to the Psychopathic Wards at Bellevue came from the very lowest strata of society, and they, as well as their friends, were usually too ignorant to give a complete history. Owing to the short time the patients remained in the hospital, the opportunities for obtaining adequate histories were necessarily limited. In view of these difficulties, therefore. the histories of 250 cases had been selected for analysis. They were those of patients admitted consecutively, and did not include those in which the defects spoken of had been marked.

Age: In the 250 cases analyzed, the age of the patients ranged from I 8 to 65 years, the majority being in the fourth and fifth decades of life. Several were under 22 years, the voungest being a woman of 18 who had contracted svnhilis at the age of 13 . The oldest was a man of 64.

Civil Condition: Of this series, 75 per cent. of the patients were married.

Nationality: Almost all nationalities were represented. There were 76 native born; 70 Germans; 48 Irish and 35 Hebrews. There were two negroes and two Japanese.

Occupation: J aborers were naturally the most numerous. Among the better class of patients were five actors, three merchants, two physicians and two lawyers.

Heredity: A family history of mental disease was obtainable in about 20 per cent. of the patients. In 12 per cent. the family history showed various disorders, such as Parkinson's disease, hysteria, epilepsy, neurasthenia, etc.

Alcoholism: In about 25 per cent. of the patients there was a distinct 
history of alcoholic abuse. In six cases, the intemperate use of alcohol was given as the chief cause.

Miscellaneous: In 12 cases the assigned cause was traumatism of the liead; in 6, overwork; in 4, grief and business worry; in 3, "stomach trouble"; in 3 , rheumatism, and in one, la griope.

Syphilis: A positive history of syphils was obtained in 99 of the male patients; about 45 per cent. In 33 others there was a strong presumptive evidence of syphilis. In 16 cases, in which specific disease was denied, there was a history of repeated miscarriages or sterility in the patients' wives. In addition, several presented superficial scars and bone enlargements. 2r gave a history of chancroids, or repeated urethritis.

Among the female patients, a positive history of syphilis was present in six cases, 20 per cent. Two gave the history of an initial lesion, and in four the husbands admitted having infected their wives. In nine, there was a history of repeated miscarriages, with a confession on the husbands" part that they had had chancre "many years previously." 'Two patients had chancroids and gonorrhea. If these incomplete histories could be regarded as indications of luetic infection. the percentage of syphilis in this series would be 80 per cent. in men and 56 per cent. in women, the average of all being 78 per cent. In tliese 250 cases, the shortest period of development after the initial lesion of syphilis was five years; the longest, 36 years.

Dr. Gregory said that in recapitulation it seemed that clinically speaking, three factors were necessary for the development of paresis. and they were, in the order of their importance: (I) hereditary or constitutional predisposition: (2) syphilis; and (3) an exciting cause, such as stress of life, mental or physical strain, trauma, or intoxications of various kinds.

Prognosis: The prognosis of a true cases of paresis, Dr. Gregory believed, was bad, and tuniformly fatal. He was inclined to think, however, that the general tendency had been to give too gloomy a prognosis as to the rapidity of the progress of the disease, for at least some of these patients. One could never be certain as to the remissions. 